\title{
PKM-KONSELING IBU HAMIL DALAM MEMENUHI KEBUTUHAN DASAR IBU SELAMA KEHAMILAN DI KELURAHAN BAGAN PETE
}

\author{
Melda Amalia \\ Program Studi DIII Kebidanan, STIKes Baiturrahim Jambi \\ email: melda.skb@gmail.com
}

\begin{abstract}
Maternal and infant mortality is very influential on the integrity and resilience of family and society, the quality of human resources, which in turn will hinder efforts to achieve national development goals. The causal factors that cause indirect or direct causes are because most pregnant women do not understand the physiological changes that occur during pregnancy so that the mother cannot adapt to physiological changes during pregnancy. The physiology of pregnancy and childbirth in general is the same, but because certain things related to the process of forming a fetus in the womb until the birth of a baby varies, the physiology of the baby's birth becomes different from one another. One of them is circulation function in pregnancy. Blood circulation from the mother for fetus will increase according to gestational age and according to the increase in weight and size of the fetus. The aim of this community service program is that expectant mothers can understand the basic needs during pregnancy both for the needs of the mother and the fetus. One effort that can be done so that the mother can understand the basic needs during pregnancy, both the needs for the mother and the basic needs for the fetus, namely by giving counseling explanations about what needs are needed by the mother and fetus.
\end{abstract}

Keyword: maternal; pregnancy; fetus

\begin{abstract}
ABSTRAK
Kematian ibu dan bayi sangat berpengaruh terhadap keutuhan serta ketahanan keluarga dan masyarakat, kualitas sumber daya manusia, yang pada gilirannya akan menghambat upaya pencapaian tujuan pembangunan nasional. Faktor penyebab yang menyebabkan terjadinya penyebab tidak langsung maupun langsung dikarenakan kebanyakan ibu hamil tidak memahami perubahan fisiologi yang terjadi selama kehamilan sehingga ibu tidak dapat berdaptasi dalam perubahan fisiologis selama kehamilan. Fisiologi kehamilan dan kelahiran bayi secara umum adalah sama, namun karena hal-hal tertentu yang berkaitan dengan proses pembentukan janin dalam rahim hingga kelahiran bayi bervariasi, maka fisiologis kelahiran bayi menjadi berbeda satu sama lain. Salah satunya fungsi sirkulasi pada kehamilan. Sirkulasi darah dari ibu kejanin akan meningkat sesuai usia kehamilan dan sesuai dengan bertambahnya berat dan besar janin. Tujuan dari program pengabdian masyarakat ini diharapkan ibu hamil dapat memahami kebutuhan dasar selama kehamilan baik kebutuhan ibu dan janin. Salah satu upaya yang dapat dilakukukan agar ibu dapat memahami kebutuhan dasar selama kehamilan baik kebutuhan untuk ibu maupun kebutuhan dasar untuk janin yakni dengan memberikan konseling penjelasan mengenai kebutuhan apa saja yang dibutuhkan ibu dan janin.
\end{abstract}

Kata kunci: Ibu; Kehamilan; Janin 


\section{PENDAHULUAN}

Kematian ibu dan bayi sangat berpengaruh terhadap keutuhan serta ketahanan keluarga dan masyarakat, kualitas sumber daya manusia, yang pada gilirannya akan menghambat upaya pencapaian tujuan pembangunan nasional. Kehamilan dan persalinan sebagai salah satu penyebab utama kematian perempuan usia reproduktif dan tinggi rendahnya Angka Kematian Ibu (AKI) secara tidak langsung menggambarkan kondisi kesehatan lingkungan serta tingkat pelayanan kesehatan terutama untuk ibu hamil, ibu melahirkan dan masa nifas. Angka Kematian Bayi (AKB) dan Angka Harapan Hidup (AHH) dipakai sebagai acuan untuk mengukur kemajuan pembangunan manusia (Martaadisoebrata, Sastrawinata dan Saifuddin,2005).

Indonesia memiliki Angka Kematian Ibu tertinggi di Asia Tenggara. Tingginya Angka Kematian Ibu di Indonesia menjadi salah satu prioritas utama dalam agenda pemerintah Indonesia. Berdasarkan data dari Departemen Kesehatan Indonesia Angka Kematian Ibu di Indonesia pada tahun 2004 berhasil diturunkan menjadi 270 per 100.000 kelahiran hidup menjadi 262 pada tahun 2005, 255 pada tahun 2006 dan 248 pada tahun 2007. Target pada tahun 2008 adalah 235 per 100.000 kelahiran hidup. Hingga akhir tahun 2009 diharapkan angka kematian ibu mencapai 226 per 100.000 kelahiran hidup dan tahun 2010 ditargetkan mencapai 125 per 100.000 kelahiran hidup. Pada tahun 2010 dan menurut target MDGs tahun 2015 diharapkan kita mencapai AKI 100. Angka kematian ibu juga masih tinggi di Indonesia. Pada tahun 2007 mencapai 228/100.000 kelahiran hidup. Angka ini jauh berada diatas angka kematian ibu di Negara Asean lainnya. Penyebab tak lansung kematian ibu ini antara lain adalah perdarahan, infeksi dan partus macet
(Martaadisoebrata, Sastrawinata dan Saifuddin,2005;MDG's 2015;SDKI, 2007).

Faktor sebab yang menyebabkan terjadinya penyebab tidak langsung maupun langsung disebabkan karena kebanyakan ibu hamil tidak memahami perubahan fisiologi yang terjadi selama kehamilan sehingga ibu tidak dapat berdaptasi dalam perubahan fisiologis selama kehamilan. Fisiologi kehamilan dan kelahiran bayi secara umum adalah sama, namun karena hal-hal tertentu yang berkaitan dengan proses pembentukan janin dalam rahim hingga kelahiran bayi bervariasi, maka fisiologis kelahiran bayi menjadi berbeda satu sama lain (Swasono, 2000). Salah satunya fungsi sirkulasi pada kehamilan. Sirkulasi darah dari ibu kejanin akan meningkat sesuai usia kehamilan dan sesuai dengan bertambahnya berat dan besar janin (Reeder, 1999).

Pertambahan berat janin berhubungan dengan kebutuhan makan ibu selama kehamilan. Ibu hamil memiliki kebutuhan makanan yang berbeda dengan ibu yang tidak hamil, karena ada janin yang tumbuh dirahimnya. Kebutuhan makanan dilihat bukan hanya dalam porsi tetapi harus ditentukan pada mutu zat-zat nutrisi yang terkandung dalam makanan yang dikonsumsi (Derek, 2005). Kebutuhan ini bertujuan untuk pertumbuhan maupun aktivitas janin yang juga membutuhkan makanan yang disalurkan melalui plasenta (Francin, 2005).

Survey awal yang dilakukan pada ibu hamil ditemukan sebagian besar ibu hamil masih mengalami ketidaknyamanan selama kehamilan yang disebabkan ketidak tahuan ibu hamil dalam menghadapi perubahan fisiologis kehamilan. Selain itu ditemukan beberapa ibu hamil kurang mengetahui kebutuhan dasar ibu dan janin selama kehamilan.

Dari uraian diatas, maka saya tertarik untuk melakukan kegiatan pengabdian kepada masyarakat dengan judul konseling ibu hamil dalam memenuhi kebutuhan dasar ibu hamil selama kehamilan. 


\section{Bentuk Kegiatan}

\section{TARGET DAN LUARAN}

1. Target

Kegiatan ini memiliki target sebagai berikut:

a. Ibu Hamil di kelurahan bagan pete mendapatkan edukasi dan konseling akan kebutuhan ibu dan janin selama kehamilan

b. Ibu hamil mendapatkan materi yang berisi akan kebutuhankebutuhan ibu dan janin selama hamil

c. Ibu hamil memahami dan mengerti kebutuhan-kebutuhan ibu dan janin selama kehamilan.

2. Luaran

Luaran Kegiatan Pengabmas ini yakni:

a. Media leaflet yang berisi materi tentang kebutuhan dasar ibu dan janin selama kehamilan.

b. Pemahaman ibu tentang kebutuhan ibu dan janin selama kehamilan

\section{METODE PELAKSANAAN}

\section{Waktu dan Tempat Pelaksanaan}

Sasaran dari kegiatan ini adalah Ibu Hamil. Kegiatan ini dilaksanakan pada Januari 2019 di Kelurahan Bagan Pete.
Bentuk Kegiatan berupa Konseling Persoanl, dan Tanya jawab tentang kebutuhan ibu dan janin selama kehamilan maupun ketidaknyamanan ibu selama kehamilan.

\section{Tahapan Pelaksanaan}

Tahapan Kegiatan pengabdian masyarakat terbagi dalam dua bentuk kegiatan, yakni:

Tabel. 1 Bentuk Kegiatan Hari I

\begin{tabular}{lll}
\hline $\begin{array}{l}\text { Kegiatan } \\
\text { penyuluhan }\end{array}$ & Kegiatan & Waktu \\
\hline
\end{tabular}

\begin{tabular}{lll}
\hline tahap pembukaan & $\begin{array}{l}\text {-Menjawab } \\
\text { salam }\end{array}$ & \\
- Memberi salam & \\
& -Memperhati \\
- Perkenalan & kan \\
& \\
- Menjalin & \\
$\begin{array}{l}\text { Hubungan Baik } \\
\text { dengan ibu }\end{array}$ &
\end{tabular}

Tahap informasi

-Mendegark 30 menit

- Melakukan Anamnesa awal an dan memperhati

- Menanyakan keluhan ibu selama kehamilan

- Menyakan riwayat pemeriksaan kehamilan sebelumnya

- Memberikan informasi akan adaptasi fisiologi selama kehamilan 
Jurnal Abdimas Kesehatan (JAK) Vol 1,No.2, Juni 2019

p-ISSN :2655-9226

e-ISSN: 2655-9218

\begin{tabular}{lcc}
\hline Penutup & $\begin{array}{c}\text {-Menjawab } \\
\text { salam }\end{array}$ & 2 menit d. \\
- Memberi salam & & \\
\hline
\end{tabular}

Berdasarkan hasil kegiatan pengabdian masyarakat didapatkan $80 \%$ ibu hamil berada pada usia kehamilan trimester II dan $20 \%$ ibu hamil berada pada usia kehamilan trimester III.

Tabel. Bentuk Kegiatan Hari II

\begin{tabular}{|c|c|c|}
\hline $\begin{array}{l}\text { Kegiatan } \\
\text { penyuluhan }\end{array}$ & Kegiatan & Waktu \\
\hline $\begin{array}{l}\text { Tahap pembukaan } \\
\text { - memberi salam } \\
\text { - Mereview } \\
\text { perkembangan } \\
\text { Keluhan/ } \\
\text { Masalah ibu } \\
\text { pada awal } \\
\text { konseling }\end{array}$ & $\begin{array}{l}\text { - Menjawab } \\
\text { salam } \\
\text { - Memperhat } \\
\text { ikan }\end{array}$ & 5 menit \\
\hline $\begin{array}{l}\text { Tahap informasi } \\
\text { - Mediskusikan } \\
\text { - kebutuhan- } \\
\text { kebutuhan ibu } \\
\text { selama kehamilan }\end{array}$ & $\begin{array}{l}\text { - Diskusi } \\
\text { - Tanya } \\
\text { jawab }\end{array}$ & $\begin{array}{l}20 \\
\text { menit }\end{array}$ \\
\hline $\begin{array}{l}\text { - Mediskusikan } \\
\text { cara pemenuhan } \\
\text { kebutuhan ibu } \\
\text { selama kehamilan }\end{array}$ & & \\
\hline $\begin{array}{l}\text { Penutup } \\
\text { - Memberi salam }\end{array}$ & $\begin{array}{l}\text { - Menjawab } \\
\text { salam }\end{array}$ & 2 menit \\
\hline
\end{tabular}

e. Ibu hamil dengan usia kehamilan trimester 2 mengetahui perubahan perubahan fisiologi yang mempengaruhi keluhan dan masalah yang sering dialami ibu

f. Semua ibu hamil memahami kebutuhan-kebutuhan dasar ibu hamil selama kehamilan

g. Ibu dengan usia kehamilan trimester 3 mendapatkan konseling tanda-tanda persalinan, dan persiapan persalinan.

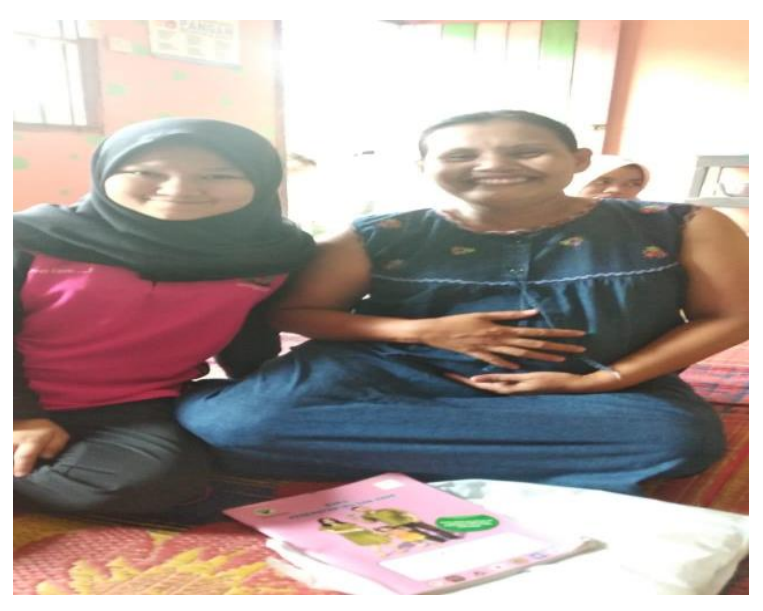

Gambar 1. Konseling Hari Pertama Ibu Hamil

\section{HASIL DAN PEMBAHASAN}

Hasil yang telah dicapai dari pengabdian masyarakat di Kelurahan Bagan Pete:

a. Ibu merasa senang dapat menyalurkan keluhan dan masalah yang dihadapinya selama kehamilan

b. Ibu mengetahui perubahan-perubahan fisiologis yang terjadi selama kehamilan

c. Ibu mengetahui kebutuhan dasar ibu hamil selama kehamilan

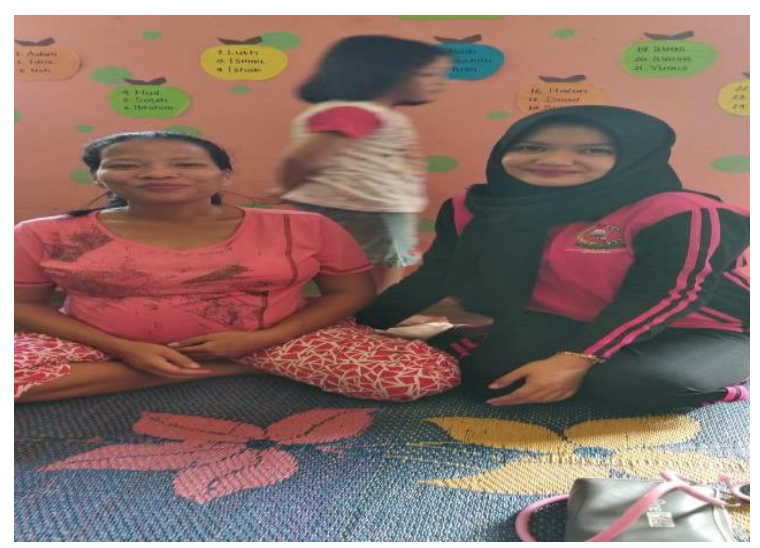


Gambar 1. Konseling Hari Pertama Ibu Hamil

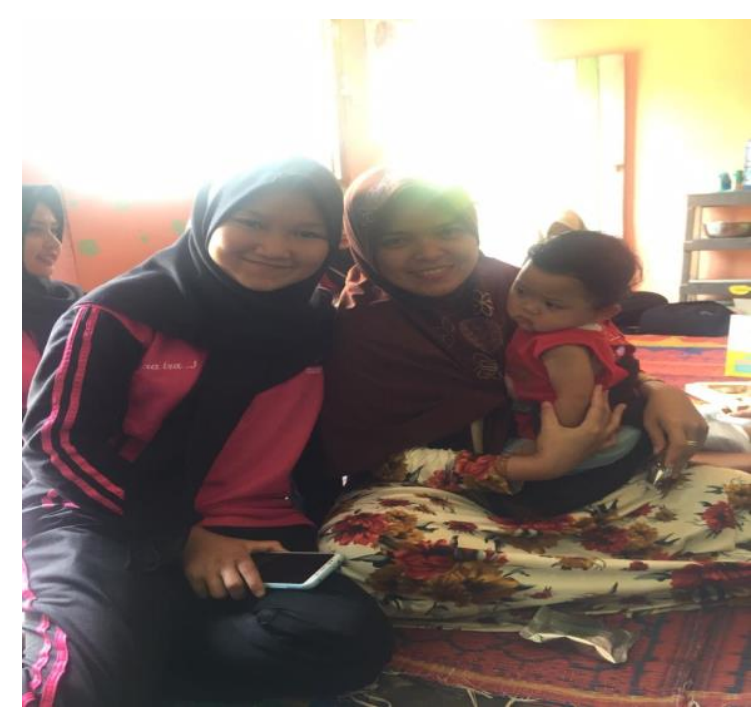

Gambar 1. Konseling Hari Kedua Ibu Hamil

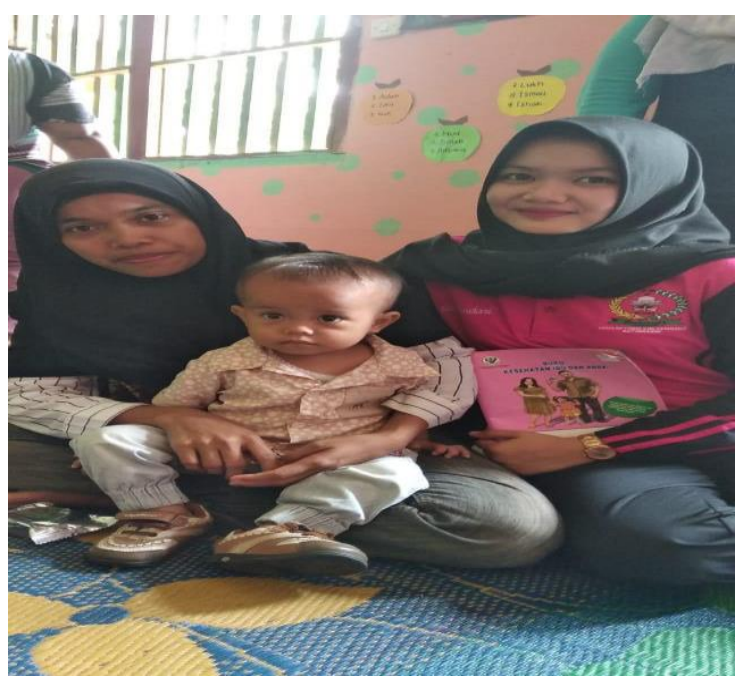

Gambar 1. Konseling Hari Pertama Ibu Hamil

\section{KESIMPULAN DAN SARAN}

\section{Kesimpulan}

Pelaksanaan pengabdian masyarakat yang dilakukan oleh dosen STIKBA untuk Meningkatan Pengetahuan Ibu hamil dalam memenuhi kebutuhan dasar selama kehamilan.

\section{Saran}

1. Melakukan kegiatan secara rutin agar ibu dapat mengatasi keluhan-keluhan selama kehamilan

2. Ibu hamil lebih aktif lagi mencari informasi akan perkembangan janin selama kehamilan.

\section{UCAPAN TERIMA KASIH}

Terima kasih disampaikan kepada Sekolah Tinggi Ilmu Kesehatan Baiturrahim yang telah memberikan dukungan dana serta kepada Dinas Kesehatan Kota Jambi yang telah memfasilitasi kegiatan ini sehingga kegiatan ini dapat terlaksana dengan baik.

\section{DAFTAR PUSTAKA}

Indonesian progress report on the Millenium Development Goals in Goals 5:Improving Maternal Health.p 56-9

Martaadisoebrata D, Sastrawinata S, Saifuddin AB. Bunga rampai obstetri dan ginekologi sosial. Yayasan Pustaka Sarwono Prawirohardjo. Jakarta,2005.

Rachmawati. (2006). Survey AKI dan AKB di Indonesia. Diperoleh dari: http://j3ffunk.blogspot.com

Reeder, S. J., Martin, L. L., \& Griffin, D. K. (2003). Maternity nursing; Family newborn and women's health care. Philadelphia: Lippincott.

SDKI. (2007). Angka kematian ibu di Indonesia.

Swasono, M. F. (2000). Kehamilan, kelahiran, perawatan ibu \& bayi. Jakarta: Penerbit Universitas Indonesia. 